\title{
OPTIMASI FORMULA LOSIO TABIR SURYA EKSTRAK KULIT BUAH NAGA SUPER MERAH (Hylocereus costaricensis)
}

\section{OPTIMIZATION FORMULA OF SUNSCREEN LOTION OF SUPER RED DRAGON (Hylocereus costaricensis) FRUIT SKIN'S EXTRACT}

\author{
Nur Saadah Daud, Musdalipah \\ Politeknik Bina Husada Kendari, Program Studi D-III Farmasi \\ Jl. Sorumba No.17, Kendari, Indonesia \\ Email: nursaadah.akfarbinhus@gmail.com (Nur Saadah Daud)
}

\begin{abstract}
ABSTRAK
Paparan sinar matahari yang berlebihan dan berlangsung lama dapat menyebabkan eritema dan kulit terbakar, penuaan dini, dan kanker kulit. Salah satu bentuk sediaan kosmetik yang dapat digunakan untuk melindungi kulit adalah losio yang mengandung zat aktif tabir surya. Ekstrak kulit buah naga super merah adalah bahan alam yang memiliki efek antioksidan dan tabir surya. Optimasi formula losio tabir surya dilakukan menggunakan metode D-optimal dengan 2 faktor yaitu ekstrak kulit buah naga super merah sebagai bahan aktif dengan kisaran konsentrasi 9-12\% dan natrium alginat 3-6\% dari seluruh komponen losio sebagai peningkat viskositas. Nilai SPF, viskositas, dan daya sebar ditetapkan sebagai respon. Losio yang dihasilkan berwarna coklat, berbentuk semipadat khas losio, homogen, beraroma khas minyak mawar, $\mathrm{pH}$ sesuai syarat SNI dengan tipe emulsi minyak dalam air (M/A). Hasil respon yang diperoleh dari 11 formula menghasilkan nilai SPF dengan kisaran 6,64-14,12, nilai viskositas $10333-13000 \mathrm{cp}$ yang memenuhi standar SNI, dan nilai daya sebar $6,52-7,92 \mathrm{~cm}$. Formula optimum hasil prediksi D-optimal menggunakan perangkat lunak Design Expert ${ }^{\circledast}$ 7.1.5 ditetapkan konsentrasi ekstrak $12 \%$ dan natrium alginat 3\%. Peningkatan konsentrasi ekstrak dan $\mathrm{Na}$ alginat menunjukkan pengaruh yang tidak signifikan terhadap ketiga respon.
\end{abstract}

Kata kunci: optimasi, losio, buah naga super merah, natrium alginat.

\section{ABSTRACT}

Skin exposure to excessive and prolonged sunlight can cause erythema, sunburn, premature aging and skin cancer. One of cosmetic preparations that can be used to protect the skin from such causes is a lotion containing a sunscreen active ingredient. The extract of super red dragon fruit's skin is a natural antioxidant agent with sunscreen effects. Optimization of sunscreen lotion formula was done using D-optimal design with 2 factors. They were the concentrations of extract of red dragon fruit's skin as an active ingredient with range of 9-12\% and sodium alginate as viscosity enhancer at range of 3$6 \%$. The SPF, viscosity, and spreading power value were defined as responses. The lotions 
were brown, semisolid (typical of lotion), homogeneous, with rose oil of scent, and $\mathrm{pH}$ value suitable to SNI requirement, and had oil-in-water $(o / w)$ of emulsion type. The responses obtained from 11 formula yield the SPF value of 6.64-14.12, the viscosity value of 10333-13000 cp which met SNI standard, and the spread power of 6.52-7.92 $\mathrm{cm}$. The optimum formula from D-optimal prediction with Design Expert ${ }^{\circledR} 7.1 .5$ software $^{2}$ was set to $12 \%$ of extract and $3 \%$ of sodium alginate. Increased concentration of extract and Na alginate showed no significant effect on all three responses.

Key words: optimization, lotion, super red dragon fruit, sodium alginate. 


\section{Pendahuluan}

Kulit merupakan organ paling luar yang langsung terpapar dengan lingkungan pro-oksidatif seperti radiasi sinar UV, obat-obatan, polusi udara, asap rokok, radiasi, alcohol, dan paparan zat tertentu. Akibatnya kulit terlihat kering dan tipis, muncul garisgaris atau kerutan halus, muncul pigmentasi kulit, terlihat tidak kencang, kusam, dan tidak segar (Mulyawan dan Suriana, 2013). Sinar matahari yang membahayakan kulit adalah radiasi ultraviolet (UV) dimana sinar ini berdasarkan panjang gelombang dan efek fisiologik dibedakan menjadi tiga yaitu (1) UVA (320-400 nm) yang memiliki efek penyinaran, menimbulkan pigmentasi sehingga menyebabkan kulit berwarna coklat kemerahan tanpa menimbulkan inflamasi sebelumnya; (2) UVB (290-320 nm) yang memiliki efek penyinaran, mengakibatkan sunburn maupun reaksi iritasi serta kanker kulit apabila terlalu lama terpapar, dan (3) UVC (200-290 nm) efek penyinaran paling kuat karena memiliki energi radiasi paling tinggi di antara ketiganya, yaitu dapat menyebabkan kanker kulit dengan penyinaran yang tidak lama (Taufikkurohmah, 2005; Dutra dkk., 2004).
Umumnya kulit memiliki mekanisme pertahanan terhadap efek toksik dari paparan sinar matahari, seperti pengeluaran keringat, pembentukan melanin, dan penebalan sel tanduk (Karmilah dan Musdalipah, 2018). Akan tetapi, pada penyinaran yang berlebihan, sistem perlindungan tersebut tidak mencukupi lagi karena banyak pengaruh lingkungan yang secara cepat atau lambat dapat merusak jaringan kulit. Oleh karena itu, diperlukan perlindungan kulit tambahan dengan dibuat sediaan kosmetika pelindung kulit, yaitu sunscreen yang mengandung senyawa tabir surya yang bekerja melindungi kulit dari radiasi UV secara langsung (Wilkinson dan Moore, 1982)

Sediaan kosmetik yang berbahan dasar alami yang berkhasiat tabir surya sangat diminati oleh masyarakat disebabkan karena adanya kekhawatiran terhadap efek samping penggunaan kosmetik berbahan dasar senyawa aktif tabir surya sintetik. Sejalan dengan hal tersebut, konsep hidup back to nature mulai diminati dan didukung pula dengan melimpahnya kekayaan alam di Indonesia (Musdalipah dan karmilah, 2018). Salah satu bahan alam yang dapat melindungi 
kulit dari sinar radiasi adalah buah naga merah. Hasil skrining fitokimia menunjukkan kulit buah naga mengandung triterpenoid, alkaloid, flavonoid dan saponin (Susanti dkk., 2012). Resiko penyakit kronis akibat senyawa radikal bebas dapat dikurangi dengan memanfaatkan peran senyawa antioksidan. Karakter utama senyawa antioksidan adalah kemampuannya untuk menangkap radikal bebas (Prakash dkk., 2011).

Selain itu, tanaman yang mengandung senyawa flavonoid dan fenolik juga diketahui mempunyai khasiat sebagai tabir surya, sehingga tanaman ini sangat berpotensi jika dibuat dalam bentuk kosmetik tabir surya (Heinrich dkk., 2010; Ismail dan Sidiqi, 2010). Ekstrak etanol 96\% kulit buah naga super merah pada nilai IC50 4602,74 ppm dikelompokkan sebagai antioksidan sangat lemah dan pada konsentrasi 900 ppm mempunyai nilai SPF 22,438 serta \%Te 6,186 dan \%Tp 5,586 yang dikategorikan sebagai suntan standar (Widyastuti dkk., 2015).

Losio adalah salah satu bentuk sediaan tabir surya yang sering digunakan. Losio memiliki beberapa sifat sebagai sumber pelembab bagi kulit, membuat tangan dan badan menjadi lembut dan mudah dioleskan. Percobaan pendahuluan menghasilkan formula losio ekstrak kulit buah naga super merah yang memiliki aktivitas tabir surya kategori proteksi ultra, tetapi proses optimasi belum dilakukan (Fuuta, 2016). Optimasi formula losio tabir surya pada penelitian ini dilakukan dengan metode rancangan D-Optimal menggunakan perangkat lunak Design Expert ver. 7.1.5. Konsentrasi ekstrak kulit buah naga super merah dan peningkat viskositas $\mathrm{Na}$ alginat ditetapkan sebagai faktor. Sedangkan nilai SPF, viskositas, dan daya sebar ditetapkan sebagai respon.

\section{Metode Penelitian}

Bahan

Buah naga super merah (Hylocereus costaricensis) (Kendari, Indonesia). Setil akohol, asam stearat, propilenglikol, metil paraben, propil paraben, tween 80 , $\alpha$-tokoferol, minyak mawar dan akuades diperoleh dari Brataco, Indonesia.

\section{Jalannya Penelitian}

1. Maserasi

Kulit buah naga super merah, dimaserasi dengan pelarut etanol 96\% (1 : 7,5 bagian pelarut) selama 3 hari, dengan sesekali diaduk. 
Penguapan pelarut pada maserat hasil penyaringan dilakukan menggunakan alat rotary evaporator (Scilogex, RE100-Pro).

2. Pembuatan losio tabir surya

Sebanyak 11 formula losio dibuat berdasarkan rancangan formula desain D-optimal sebagaimana tertera pada Tabel 1 . $\mathrm{Na}$ alginat dilarutkan ke dalam akuades panas hingga larut sempurna, kemudian dicampurkan bersama bahan fase air lain (propilenglikol, metil paraben, dan Tween 80) (campuran 1) pada cawan porselin dan dipanaskan hingga suhu $70{ }^{\circ} \mathrm{C}$. Campuran bahan fase minyak (propil paraben, $\alpha$-tokoferol, asam stearate, dan setil alkohol) dalam cawan proselin dilebur hingga suhu $70{ }^{\circ} \mathrm{C}$ (campuran 2). Selanjutnya dimasukkan campuran 1 dan campuran 2 ke dalam mortir panas secara bersamaan dan digerus hingga homogen (campuran 3). Ekstrak kulit buah naga super merah dan minyak mawar ditambahkan sedikit demi sedikit ke dalam campuran 3, lalu digerus hingga homogen dan membentuk massa losio. Pada sediaan yang telah dibuat selanjutnya dilakukan uji organoleptik, uji homogenitas, uji tipe emulsi, pengukuran $\mathrm{pH}$ sediaan, serta uji 3 respon.

Tabel 1. Rancangan percobaan optimasi formula losio tabir surya ekstrak kulit buah naga super merah dengan rancangan D-optimal

\begin{tabular}{ccccc}
\hline \multirow{2}{*}{ Run } & \multicolumn{2}{c}{ Faktor } & \multicolumn{2}{c}{ Bahan Tambahan Lain } \\
\cline { 2 - 5 } & (Ekstrak \%) & (Na alginat \%) & Bahan & Konsentrasi (\%) \\
\hline 1 & 12 & 3 & Setil alkohol & 5 \\
2 & 9 & 6 & Asam stearat & 2 \\
3 & 10,5 & 4,5 & Propilenglikol & 5 \\
4 & 12 & 3 & Metil paraben & 0,18 \\
5 & 12 & 3 & Propil paraben & 0,02 \\
6 & 10 & 5 & Tween 80 & 4 \\
7 & 11,25 & 3,75 & a-tokoferol & 0,01 \\
8 & 9 & 6 & Minyak mawar & q.5 \\
9 & 9,75 & 5,25 & Akuades & ad 100 \\
10 & 11 & 4 & & \\
11 & 9 & 6 & & \\
\hline
\end{tabular}


3. Pengukuran nilai SPF (Sun Protection Factor)

Sampel losio seberat 0,5 gram dilarutkan dalam $25 \mathrm{~mL}$ etanol 96\% (20.000 ppm). Sampel diukur absorbansinya dengan alat spektrofotometer UV-Vis (Genesys $10 S$ UV-Vis, US) tiap $5 \mathrm{~nm}$ pada rentang panjang gelombang dari 290 $\mathrm{nm}-320 \mathrm{~nm}$ dengan etanol 96\% sebagai blanko (Daud dkk., 2016;
Mansur dkk., 1986). Perhitungan nilai SPF menurut Mansur dkk. (1986) menggunakan persamaan berikut:

$S P F=C F \times \sum_{290}^{320} E E(\lambda) \times I(\lambda) \times A b s(\lambda)$

Keterangan: $E E=s p e k t r u m$ efek eritemal, I=intensitas spektrum sinar, A=serapan produk tabir surya, $\mathrm{CF}=$ correction factor, Nilai EE x I adalah suatu konstanta yang telah ditentukan (Tabel 2).

Tabel 2. Nilai EE x I pada panjang gelombang 250-350 nm

\begin{tabular}{cc}
\hline Panjang gelombang $(\boldsymbol{\lambda}, \mathbf{n m})$ & $\mathbf{E E ~ x ~ I ~}$ \\
\hline 290 & 0,0150 \\
295 & 0,0817 \\
300 & 0,2874 \\
305 & 0,3278 \\
310 & 0,1864 \\
315 & 0,0839 \\
320 & 0,0180 \\
Total & 1 \\
\hline
\end{tabular}

4. Uji viskositas sediaan

Uji viskositas dilakukan menggunakan viskometer (Rion VT06F, Japan). Pemilihan ukuran rotor disesuaikan dengan kekentalan sampel. Rotor nomor II dipasang dengan kecepatan 62,5 rpm.

5. Uji daya sebar sediaan
Losio sebanyak 0,5 gram diletakkan di tengah-tengah kaca $A$ lalu ditutup dengan kaca B. Losio dalam kaca tersebut diberikan beban sebanyak 100 gram lalu dibiarkan menyebar. Diameter pola yang terbentuk diukur secara vertikal dan horizontal menggunakan penggaris. 
Nilai rata-rata keduanya ditetapkan sebagai diameter daya sebar.

6. Analisis data

Nilai signifikansi respon dilihat dari analisis ANOVA dalam Design Expert $^{\circledR} \quad 7.1 .5$ pada taraf kepercayaan 95\%. Formula optimum diperoleh dari hasil prediksi Design Expert $^{\circledR}$ 7.1.5, dengan nilai desirability tertinggi. Verifikasi formula optimum dianalisis dengan Independent-Sample $T$ Test menggunakan perangkat lunak SPSS dengan taraf kepercayaan 95\% $(\alpha=0,05)$.

\section{Hasil dan Pembahasan}

Ekstrak kulit buah naga super merah yang diperoleh berwarna coklat kemerahan karena adanya senyawa antosianin, dimana senyawa ini memberikan warna merah hingga coklat pada buah-buahan. Konsentrasi ekstrak kulit buah naga super merah yang digunakan pada 11 formula yang dibuat adalah 9-12\%. Kisaran konsentrasi ini merujuk pada penelitian yang menyatakan bahwa sediaan Iosio dengan konsentrasi ekstrak kulit buah naga super merah 2,5; 5; dan 7,5\% mampu memberikan nilai SPF dengan nilai tertinggi yaitu 17,758 (kategori

proteksi ultra) (Fuuta, 2016).

Konsentrasi tersebut selanjutnya ditingkatkan dengan tujuan untuk mendapatkan sediaan losio dengan efek tabir surya yang lebih tinggi lagi. Sedangkan konsentrasi $\mathrm{Na}$ alginat yang digunakan adalah hasil percobaan pendahuluan yaitu pada konsentrasi 36\% dari seluruh komponen losio yang dapat menghasilkan sediaan losio yang baik.

Kesebelas formula menghasilkan losio yang berbentuk semipadat, berwarna coklat muda hingga coklat, dan homogen yang ditandai dengan tidak adanya partikelpartikel kasar pada permukaan kaca objek dan warna sediaan yang merata. Warna yang terbentuk disebabkan karena adanya kandungan senyawa antosianin pada ekstrak. Sedangkan aroma losio adalah aroma khas minyak mawar yang digunakan sebagai pewangi.

Tipe emulsi losio adalah minyak dalam air $(M / A)$, sesuai dengan yang diharapkan. Tipe emulsi ini memiliki banyak keuntungan di antaranya mudah dibilas dengan air dan tidak lengket saat dipakai. 
Tabel 3. Hasil evaluasi respon SPF, viskositas, dan daya sebar losio ekstrak kulit buah

\begin{tabular}{cccc}
\multicolumn{3}{c}{ naga super merah } \\
\hline Run & Respon 1 (SPF) & Respon 2 (Viskositas) & Respon 3 (Daya Sebar) \\
\hline 1 & 7,64 & 10667 & 7,48 \\
2 & 6,72 & 13000 & 7,92 \\
3 & 6,61 & 11333 & 6,60 \\
4 & 9,92 & 10333 & 6,82 \\
5 & 14,12 & 10667 & 6,85 \\
6 & 6,64 & 12000 & 6,52 \\
7 & 6,95 & 11000 & 6,57 \\
8 & 8,84 & 11667 & 6,27 \\
9 & 7,13 & 11667 & 6,93 \\
10 & 6,80 & 10000 & 7,18 \\
11 & 7,81 & 11000 & 6,58 \\
\hline
\end{tabular}

Nilai $\mathrm{pH}$ sediaan losio berkisar antara 4,58-4,83, yang memenuhi syarat SNI 16-4399-1996 tentang sediaan tabir surya $\mathrm{pH} 4,5-8,0$ (SNI, 1996). Nilai $\mathrm{pH}$ sediaan dapat mempengaruhi stabilitas, kenyamanan, dan keamanan penggunaan sediaan pada kulit.

Hasil pengukuran ketiga respon (SPF, viskositas, dan daya sebar) terhadap 11 formula losio dapat dilihat pada Tabel 3. Pengukuran nilai SPF dilakukan dengan tujuan untuk mengetahui seberapa besar nilai proteksi dari suatu sediaan tabir surya dalam melindungi kulit dari paparan sinar UV. Kemampuan menahan radiasi UV dari tabir surya dinilai dalam faktor proteksi cahaya (Sun Protection
Factor/SPF) (Fuuta, 2016). Semakin tinggi konsentrasi ekstrak kulit buah naga super merah, maka diharapkan konsentrasi kandungan antosianin juga semakin besar, sehingga nilai SPF losio pun semakin tinggi. Kandungan beberapa senyawa aktif seperti antosianin berperan memberikan efek tabir surya yang melindungi kulit atau sel dari kerusakan dengan menyerap cahaya ultraviolet (Widyastuti dkk., 2015). Losio dengan ekstrak kulit buah naga super merah konsentrasi $12 \%$ memiliki nilai SPF tertinggi 14,12 (kategori proteksi maksimal).

Viskositas merupakan tahanan suatu cairan untuk mengalir, makin tinggi nilai viskositas maka semakin besar tahanannya untuk mengalir. 
Syarat nilai viskositas sediaan tabir surya menurut SNI 16-4399-1996 yaitu antara 2000-50000 cp (Fuuta, 2016). Viskositas yang terlalu tinggi akan mengurangi tingkat kenyamanan penggunaan karena sulit mengalir, sehingga saat mengeluarkan sediaan dari kemasan juga menjadi sulit. Viskositas yang rendah juga tidak diharapkan, hal ini dikarenakan bila sediaan terlalu encer, maka sediaan akan menetes saat diaplikasikan pada kulit sehingga sediaan tidak tinggal seluruhnya pada permukaan kulit. Berdasarkan pertimbanganpertimbangan tersebut, maka viskositas suatu sediaan harus optimum sesuai tujuan aplikasi (Martin dkk., 1993). Nilai viskositas yang dihasilkan (Tabel 3) berada dalam rentang antara 10333$13000 \mathrm{cp}$, sehingga dapat dikatakan bahwa semua formula yang dikembangkan memenuhi persyaratan viskositas losio menurut SNI.

Pengujian daya sebar bertujuan untuk melihat kemampuan penyebaran sediaan losio pada saat penggunaan di permukaan kulit. Losio diharapkan mampu menyebar dan mudah saat diaplikasikan tanpa memerlukan tekanan yang berarti. Syarat daya sebar untuk sediaan topikal adalah $5-7 \mathrm{~cm}$, yang menunjukkan konsistensi semisolid yang sangat nyaman dalam penggunaannya (Garg dkk., 2002). Pada umumnya sediaan dengan viskositas yang berbeda-beda, akan menghasilkan daya sebar yang berbeda pula, karena hambatan pada masing-masing sediaan untuk menyebar berbeda juga besarnya. Daya sebar yang baik menyebabkan kontak antara obat dengan kulit menjadi luas, sehingga absorpsi obat ke kulit berlangsung cepat.

Hasil persamaan D-optimal (Tabel 4) menunjukkan pengaruh masing-masing komponen faktor maupun interaksinya terhadap nilai SPF, viskositas, dan daya sebar. Notasi positif (+) dalam persamaan menunjukkan bahwa peningkatan konsentrasi ekstrak kulit buah naga super merah dan $\mathrm{Na}$ alginat memberi efek positif (kenaikan) terhadap persentasi nilai SPF, viskositas, dan daya sebar losio. Hasil analisis dengan Design Expert 7.1.5 program Doptimal menghasilkan model yang tidak signifikan untuk ketiga respon $(p>0,05)$, sementara analisis lack of fit juga menunjukkan hasil yang tidak signifikan $(p>0,05)$. 
Tabel 4. Persamaan D-optimal hasil evaluasi sifat fisik (respon) losio ekstrak kulit buah naga super merah

\begin{tabular}{lllc}
\hline \multicolumn{1}{c}{ Respon } & Persamaan D-Optimal (Aktual) & p-Value & Lack of Fit \\
\hline SPF & $\mathrm{Y}=2,31 \mathrm{~A}+8,76 \mathrm{~B}-1,21 \mathrm{AB}$ & $0,0621^{*}$ & $0,9911^{*}$ \\
Viskositas & $\mathrm{Y}=619,10 \mathrm{~A}+1212,18 \mathrm{~B}-16,20 \mathrm{AB}$ & $0,0535^{*}$ & $0,6803^{*}$ \\
Daya Sebar & $\mathrm{Y}=0,62 \mathrm{~A}+1,29 \mathrm{~B}-0,12 \mathrm{AB}$ & $0,7345^{*}$ & $0,9401^{*}$ \\
\hline
\end{tabular}

Keterangan: $A=$ komponen ekstrak kulit buah naga super merah; $B=$ komponen $\mathrm{Na}$ alginate; $A B=$ interaksi antara komponen $A$ dan $B ;{ }^{*}=$ model tidak signifikan.

Penentuan formula optimum dilakukan berdasarkan pendekatan desirability paling besar, yang bermakna terdapat kedekatan antara hasil uji formula tersebut dengan nilai yang diharapkan untuk bisa memenuhi persyaratan. Desirability merupakan nilai yang besarnya $0-1$, dimana semakin mendekati satu artinya semakin tinggi kemungkinan mendapatkan nilai respon yang diinginkan (Montgomery dan Runger, 2003). Nilai desirability ini sangat dipengaruhi oleh target atau goal yang ingin dicapai dalam memperoleh formula optimum. Goal yang ingin dicapai dalam penelitian ini yaitu (1) nilai SPF dengan goal maximize, karena diharapkan losio yang dihasilkan dapat memiliki nilai SPF yang tinggi dengan nilai lower-upper 9-12\%, (2) viskositas dengan goal in range karena diharapkan diperoleh losio dengan nilai viskositas memenuhi syarat SNI 16-4399-1996, yaitu 2000-50000 cp, dan (3) nilai daya sebar dengan goal maximize, karena diharapkan diperoleh losio dengan kemampuan dapat menyebar pada permukaan kulit dengan baik, dengan nilai lower-upper $5-7 \mathrm{~cm}$.

Hasil optimasi memberikan 2 solusi formula optimum, dengan alternatif konsentrasi ekstrak kulit buah naga super merah dan $\mathrm{Na}$ alginat. Solusi formula nomor 1 adalah yang dipilih sebagai formula optimum losio dengan konsentrasi ekstrak $12 \%$ dan Na alginat $3 \%$. Solusi nomor 1 mempunyai nilai desirability paling mendekati nilai 1 yaitu 0,684 , dibandingkan dengan nilai desirability solusi formula nomor 2 yaitu 0,375 . Tabel 5 menunjukkan hasil verifikasi terhadap solusi formula optimun nomor 1 adalah berbeda tidak signifikan pada semua respon (Sig. (2tailed) $>0,05$ ) pada taraf kepercayaan 95\%. Hasil ini menyatakan bahwa metode D-optimal dengan perangkat 
lunak Design Expert 7.1.5 dapat memprediksi formula losio ekstrak kulit buah naga super merah dengan respon
SPF, viskositas, dan daya sebar yang optimum.

Tabel 5. Hasil verifikasi formula optimum prediktif D-optimal

\begin{tabular}{ccccc}
\hline Respon & Hasil Prediksi & Hasil Verifikasi & Sig. (2-tailed) & Kesimpulan \\
\hline SPF & 10,40 & 10,44 & 0,993 & Tidak signifikan \\
Viskositas $(\mathrm{cp})$ & 10482,5 & 10666,7 & 0,636 & Tidak signifikan \\
Daya sebar $(\mathrm{cm})$ & 7,05 & 6,95 & 0,090 & Tidak signifikan \\
\hline
\end{tabular}

Nilai Sig. (2-tailed) >0,05 = tidak signifikan (valid)

\section{Kesimpulan}

Formula losio tabir surya yang dihasilkan memenuhi syarat evaluasi fisik sediaan. Faktor ekstrak kulit buah naga super merah dan $\mathrm{Na}$ alginat pada sediaan losio tabir surya memberikan pengaruh yang tidak signifikan terhadap respon SPF, viskositas, dan daya sebar. Formula optimum losio tabir surya ekstrak kulit buah naga super merah adalah formula dengan komposisi ekstrak $12 \%$ dan $\mathrm{Na}$ alginat $3 \%$.

\section{Ucapan Terima Kasih}

Terima kasih kepada Direktorat Riset dan Pengabdian Masyarakat Kementerian Ristekdikti, atas Hibah Penelitian Dosen Pemula tahun anggaran 2017.

\section{Daftar Pustaka}
Dutra, E.A., Oliveira, D.A.G.dC.e., KedorHackmann, E.R.M., Santoro, M.I.R.M. 2004. Determination of sun protection factor (SPF) of sunscreens by ultraviolet spectrophotometry. Brazilian Journal of Pharmaceutical Sciences, 40(3):381-385.

Daud, N.S., Al Hajri, L.O.Z., Ervianingsih. 2016. Formulasi lotion tabir surya ekstrak etanol beras merah (Oryza nivara). Jurnal IImiah Ibnu Sina, 1(2):143-150.

Fuuta, S. 2016, Formulasi Lotion dan Penentuan Nilai Sun Proctection Factor (SPF) Ekstrak Kulit Buah Naga Super Merah (Hylocereus costaricensis). KTI. Kendari: Akademi Farmasi Bina Husada Kendari.

Garg, A., Aggarwal, D., Garg, S., dan Singla, A.K. 2002. Spreading of semisolid formulation: an update. Pharmaceutical Technology, 2002:84-102. 
Heinrich, M., Barnes, J., Gibbons, S., dan Williamson, E.M. 2010. Farmakognosi dan Fitoterapi. Jakarta: Penerbit Buku Kedokteran EGC.

Ismail, Z., Sidiqi, J. 2010. Developing herbs for cosmetics. Prosiding Seminar Nasional Kosmetika, Yogyakarta, Universitas Ahmad Dahlan.

Karmilah dan Musdalipah. 2018. Formulasi Krim Anti Jerawat Ekstrak Ampas Teh Hijau. Jurnal Insan Farmasi Indonesia, 1(1):26-33.

Mulyawan, D. dan Suriana, N. 2013. A-Z Tentang Kosmetik. Jakarta: PT Alex Media Komputindo.

Mansur, J.D.S., Breder, M.N.R., Mansur, M.C.D., Azulay, R.D. 1986. Determination of sun protection factor by spectrophotometric methods. Anais Brasileiros De Dermatologia, 61(3):121-124.

Martin, A.N., Swarbick, J., Cammarata, A. 1993. Farmasi Fisik II. Edisi III. Jakarta: UI-Press.

Musdalipah dan Karmilah. 2018. Efektivitas ekstrak daun cabai rawit (Capsicum frutescents $\mathrm{L}$ ) sebagai penumbuh rambut terhadap hewan uji kelinci (Oryctolagus cuniculus). Riset Informasi Kesehatan, 7(1):8388.

Montgomery, D., Runger, G. 2003. Applied Statistic and Probability for Engineer. $3^{\text {rd }}$ ed. New York: John Wiley \& Sons Inc.

Prakash, A., Rigelhof, F., Miller, E. 2011. Antioxidant activity. European Review for Medical and Pharmacological Sciences, 15(4):376-378.

Susanti, E.V.H., Utomo, S.B., Syukri, Y., Redjeki, T. 2012. Phytochemical screening and analysis polyphenolic antioxidant activity of methanolic extract of white dragon fruit (Hylocereus undatus). Indonesian Journal of Pharmacy, 23(1):60-64.

SNI 16-4399-1996. Sediaan Tabir Surya. Jakarta: Badan Standardisasi Nasional.

Taufikkurohmah, T. 2005. Syntesis of pmethoxy-cynnamil-pmetoxycinamate from ethyl $p$ methoxycinamat was isolated from dried rhizome Kaempferia galanga $\mathrm{L}$ as sunscreen compound. Indonesian Journal of Chemistry, 5(3):193-197.

Wilkinson, J., Moore, R. 1982. Harry's Cosmeticology. $7^{\text {th }}$ ed. New York: Chemical Publishing Company.

Widyastuti, Fratama, R.I., Seprialdi, A. 2015. Pengujian aktivitas antioksidan dan tabir surya ekstrak etanol kulit buah naga super merah (Hylocereus costaricensis (F.A.C.Weber) Britton \& Rose). Scientia, 5(2):69-73. 